\title{
Analysis on Social Intervention of Occupational Burnout of Rural Grassroots Teachers
}

\author{
Gongying $\mathrm{Li}$ \\ Eastern International Art College \\ Zhengzhou University of Light Industry \\ Zhengzhou, China 451450
}

\begin{abstract}
Currently, the occupational burnout of teachers has become a social issue, especially for the occupational burnout of rural grassroots teachers, and social factor has become the main cause for the occupational burnout of teachers. This article comes up with conducting social intervention in the occupational burnout of rural grassroots teachers from two aspects of the macro environment and mesolevel organization environment, in order to solve the occupation burnout dilemma of rural grassroots teachers.
\end{abstract}

Keywords-occupational burnout; rural grassroots teachers; social intervention

\section{INTRODUCTION}

The occupational burnout of teachers is a social issue, and its forming is intrinsically related to the individual reason of teachers, and must have deeper social factors though. Various social factors surrounding the teachers must have produced an unshaped pressure to the psychology of teachers, thus inducing the burnout. Therefore, it is especially necessary to conduct social intervention in the occupational burnout of rural middle school teachers.

\section{REGULATING AND CONTROLLING THE ADVERSE FACTOR IN THE MACRO SOCIETY, TO RELIEVE THE OCCUPATIONAL BURNOUT OF TEACHERS}

\section{A. Promoting the Salary and Welfare of Grassroots Teacher, and Substantially Improving the Social Status of Rural Teachers}

The economic status of teachers is the basis and mark for its social status, and the thin salary makes the social status of teachers be not able to be raised substantially. It is widely considered by the oversea educators that, "among the elements affecting the status of teachers", the evaluation on the importance of teachers' work and the respect on the teachers are very importance, which depend on the economic status of teachers largely" though. American educators pointed out more clearly that, "if the issue of dropping of teachers' salary and social status is not dealt with, the educational reform is only empty talk." In the report of special work group for educational issues invited by American Carnegie Commission, one of the very important suggestions is, "to increase the teachers' salary, make it higher than that of other profession for encouraging young people of wisdom to be happy to choose the job as teachers." The economic status and social status of teachers are closely linked, and it is only a meaningless empty talk to discuss the social status of teachers without dealing with the economic status.

Currently, common people think the income of teachers is raised, and teachers shall be satisfactory. In fact, such a thought has ignored the fact that the increase of teachers' salary is only comparative with those of common physical labors and the persons without receiving higher educations. Once compared with the incomes of other professionals with the same level higher education, it can be found the income and social status of teachers are not high in fact. Under the condition that the economic life of teachers (especially the rural grassroots teachers) is very embarrassed, teachers being disappointed extremely find that the job of teachers is so poor and helpless when looking to the intellectuals in other profession. Then, some teachers are trapped in wait-and-see and hesitation, and the uneasiness and unrest take them, so that the teaching does not have such important meaning, and what stands on the platform is just the body of the teacher, and the heart has left, which has passion and working will for life. So, such teachers have occupational burnout sooner or later. Therefore, the state must continue to improve the salary system of teachers and forcefully promote the economic status and material benefits of the grassroots teachers, so that the occupational burnout of grassroots teachers can be prevented effectively. The government can make efforts from the following several aspects:

1) Changing the practices of requiring teachers to make contribution in tradition and social psychology without caring for their material benefits. It has been the fundamental requirements for the qualification of teachers at home and abroad since ancient times, without an exception almost in any country. However, it is not so happy in terms of economic status of the teachers for such higher requirement. Whether it is in eastern and western country, education seems to be the work of people who should be dedicated. So, teachers shall not pursue the material benefit, and should be poor. When teachers get some honors, people tend to give them spiritual encouragement, and ignore the material awards. However, the job of teacher is not far away from other professions in society, and teacher's job is also a social occupational role created by social division of labor, 
and doing a kind of social work. Such work is the same as other professional work in society, having its necessary social value for existing, and the specialty of this job determines the job of a teacher has teaching position requirements differing from and being higher than other professions. As the social members and professionals specialized in a professional field, teachers are obviously the same as other workers in other profession, to be social labor, eligible for enjoying the obligations and rights brought by the social division of labors.

2) Perfecting the legal system and strengthening the force of legal execution. We shall practice the quarterly report system for the release of teachers' salary strictly, and strength supervision on the embezzlement of educational fund, for conducting real management of education by law. It is impossible to solve the salary issue of rural teachers by consciousness under the market economic condition. Teachers' salary management system adapting to the market economic development requirement must be established, with strict legal system and scientific management system.

3) Absorbing the advanced experience of international teachers' salary system, for modifying and perfecting the salary system of our country. There is one important feature in the salary system of all countries, which is to study the corresponding rewards level and standards by specifying the qualification condition of teachers at various level first by the state, which is used as the base for the employment unit to make recruiting, evaluation and promotion and pay the corresponding salary, i.e. the object for deciding salaries is job titles, and the effect of personal qualification (education experience and length of service must be based on the job title, and shall not steal the show. Under such condition, increase of teachers' salary shall rely on the natural salary promotion and salary increase for job level upgrading. The natural salary promotion means the salary rises automatically annually with the increase of length of service; and the salary increase for job level upgrading is realized by entering a higher level of job title for rise of salary. Such multiple factors determining the salary are beneficial for mobilizing the activity of teachers. Therefore, it is the key to abide by the customs of all other countries to change the current teachers' salary system to one based on the job title, besides, how to realize the fairness and justness in the actual operation (especially for rural grassroots schools) is also a key.

\section{B. Improving the Social Macro Environment for Forming Good Social Support Network}

To prevent the occupational burnout of rural teachers, there must be a good macro social atmosphere for rural grassroots teachers, and the whole society shall pay attention and participate in it, for forming a good social support network.

First, raising the social status of teachers to the same height as the society requires for teachers. The status and function of teachers shall be linked together dialectically. In recent years, though the salary of rural teachers has been promoted remarkably, the social status of rural teachers is still low, having a distance compared with the responsibility they shoulder. Regarding this point, the policy maker of the state educational regulation has compelling obligations. While making the relevant law and regulations, one must acknowledges fully the feature of education work in the new era, and new issues faced by the teachers, to really reflect the teachers' requirement and substantially maintain the legal interest of the teachers, especially that of rural grassroots teachers, to make them feel really the respect from the whole society.

Second, forming a good atmosphere of public belief for the occupational image of teachers. As the public belief has deep effect on the occupation attitude and work performance of teachers. In an atmosphere of public belief and public support, teachers will show confidence and hard working, and form high professional self-respect sense, and see the educational work as a cause to be pursued which make them have positive and active view, thus making teachers not have occupational burnout in their work.

Thirdly, the society shall set up a reasonable expectation on teachers. Teachers are real people, and not real oracles. The society and public opinion shall understand and support the specialty of the profession of teachers, and students' parent and student shall both set up a reasonable expectation on the ability and function of teachers, not pushing the social and family obligation to teachers. It is completely necessary for the whole society to monitor the teachers, and teachers welcome such monitoring, but this monitoring must be fair and proper. Only in this way, social opinion can be the assisting force not the resisting force for teachers' work. Therefore, educational management sector and mass media shall guide the common public people well to make them have a correct understanding for teachers.

\section{Enforcing the Developing Teachers' Evaluation System}

How to design a good system is the most urgent and substantial issue for China that have to be solved currently. The famous economist of new system Douglass.C.North thinks, system is the rule of the game for society, specific irrigation frame shall be provided for various economic, political and social organizations. As the evaluation for teachers has close relation to their vital benefit such as teachers' development, job title promotion, economic income and so on, the fairness of the teachers' evaluation will affect the work attitude and passion of teachers greatly. In actual investigation, the author finds the current evaluation for rural teachers is usually final, paying attention to the summary and evaluation of teachers' teaching, only conducting simple evaluation, appraisal and admission for the past work. The evaluation method is single, linked directly to fame and benefit, with a few teachers benefiting from it as a result, which is not beneficial to mobilize the work activity of most rural teachers. Based on this, we must rethink the past evaluations for enforcing the developing teachers' evaluation.

The so-called developing teachers' evaluation is to formulate the development target admitted by both sides of the coupled evaluator and evaluated according to a certain 
development target and development value, and the evaluator and evaluated take the responsibility together, by using methods such as interview of evaluation and developing technology for evaluation, to make value judging for the quality development, work duty and work performance of the evaluated, making the evaluated acquire information from multiple channels of the developing education evaluation activity, for continuously promoting his or her professional development, continuously understand oneself, develop oneself and perfect oneself, in order to promote his or her education teaching ability and level, and finally realizing the double direction development target of both individual of teacher and the whole of the school, a few teacher and the whole teachers, current reality and future ideal.

First, the evaluation takes the promotion of professional development of rural grassroots teachers as the target. Such an evaluation is a kind of formative evaluation, facing to the future, and it not only cares for the achievement of teachers in the past, but also determine the future profession development needs according to the teacher's performance in the past, for formulating the professional development target for the teacher and identify the future professional development direction for the teacher.

Second, playing the main role of teachers in the evaluation, encouraging teachers to participate actively in the whole process of evaluation. Teachers know themselves the best, and know about their work background and educational object the most clearly, and know the advantages and difficulty in their work the most. Therefore, evaluations for teacher must bring the action the teacher himself into full play, stressing on the teachers' main role in the evaluation. Teachers are not only the main body of the evaluation, but also the active participant to the evaluation activity, encouraging teachers to join in it democratically for self evaluation and self rethinking the educational practice. Meanwhile, we should create a wide atmosphere for encouraging teachers to conduct reflective teaching.

Thirdly, respecting the individual difference of teachers. As teachers have huge difference on aspects of personality, professional qualification, educational teaching style and work background, which exist objectively, personalized evaluation standard shall be set up while observing the objective difference of teachers, together with personalized evaluation key point and corresponding evaluation method. For different teachers there should be different evaluation level, for benefiting teachers to form a good self-running and self disciplined circulation.

Fourthly, the evaluation methods shall fully boost the main body of teachers, to evaluate teachers' creative work fully and objectively by using multiple evaluation method. School leaders and the evaluated teacher both are main body for the developing teachers' evaluation. And the developing teachers' evaluation is one letting workmates, students' parent and student join in together, to make teachers get feedback information from multiple channels, for better rethink and improve the education and teaching.

\section{REGUlating THE AdVERSE FACTOR IN THE MESO- LEVEL MINOR ENVIRONMENT, FOR RELIEVING THE OCCUPATIONAL BURNOUT OF TEACHER}

\section{A. School Practices Democratic Management, for Setting Up Good Organization Atmosphere}

Other research results show that, the organization management of school environment is one of the most important affecting factors for the occupational burnout of teachers. Based on this, the organizing management of school environment shall practice the management mode of democracy and openness, encouraging teachers to release their negative feelings and giving teachers more autonomy and freedom, providing chances for teachers to participate in the school management and decision making of school. Various level school managers especially the schoolmaster shall create a democratic and cooperative school atmosphere for teachers by all effective means, to enhance their responsibility sense and stability sense, to relieve pressures in wok and reduce the possibility for the occupational burnout to happen.

\section{B. Creating Good Campus Culture, to Form Harmful Interpersonal Atmosphere}

School should make all efforts to perfect the teaching and cultural life facility and beautify the campus to satisfy the teaching and education and cultural life requirements of teachers. School has various shaped and unshaped, formal and informal organization structure and interpersonal relations, and teachers communicate and interact in such a interpersonal network, to form a kind of school culture. Such an interpersonal atmosphere and school culture will affect the behavior and work passion of the teachers."School atmosphere may not encourage or even hinder teachers to make analysis and reaction to their own teaching, resulting in teachers taking self defense mode for the professional study, which makes their study stop quickly as a result, and teaching becomes to do the routine and be conservative, lack of doubt." Besides, if school atmosphere is not harmony, full of individualism, and teachers lack of communication and encouragement, even attack each other, which will make teachers produce the occupational burnout. Good school culture and interpersonal atmosphere make teachers produce of a sense of pride, conducive of promotion of work passion. Therefore, we should set up good campus culture actively, strive to create a warm, harmony interpersonal atmosphere for relieving the occupational burnout of teachers.

\section{REFERENCES}

[1] Jizong Shang: "Requirement, rewards and training for primary and middle school teachers of foreign countries", Tianjin Educational Publishing House, edition of 1986, pages 192 to 204.

[2] Rongming Chen: "Theory and Practice of Modern Education", Shanghai Educational Publishing House, edition of 1999, page 141.

[3] Binhua Wang: "Developing Evaulation System of Teachers", East China Normal University Press, edition of 1998.

[4] Jianwei Rao: "Professional development of teachers" [M], Taiwan Wunan Publishing Corporation, edition of 1996. 